Prepared in cooperation with the U.S. Environmental Protection Agency and the National Oceanic and Atmospheric Administration

\title{
Data Categories for Marine Planning
}

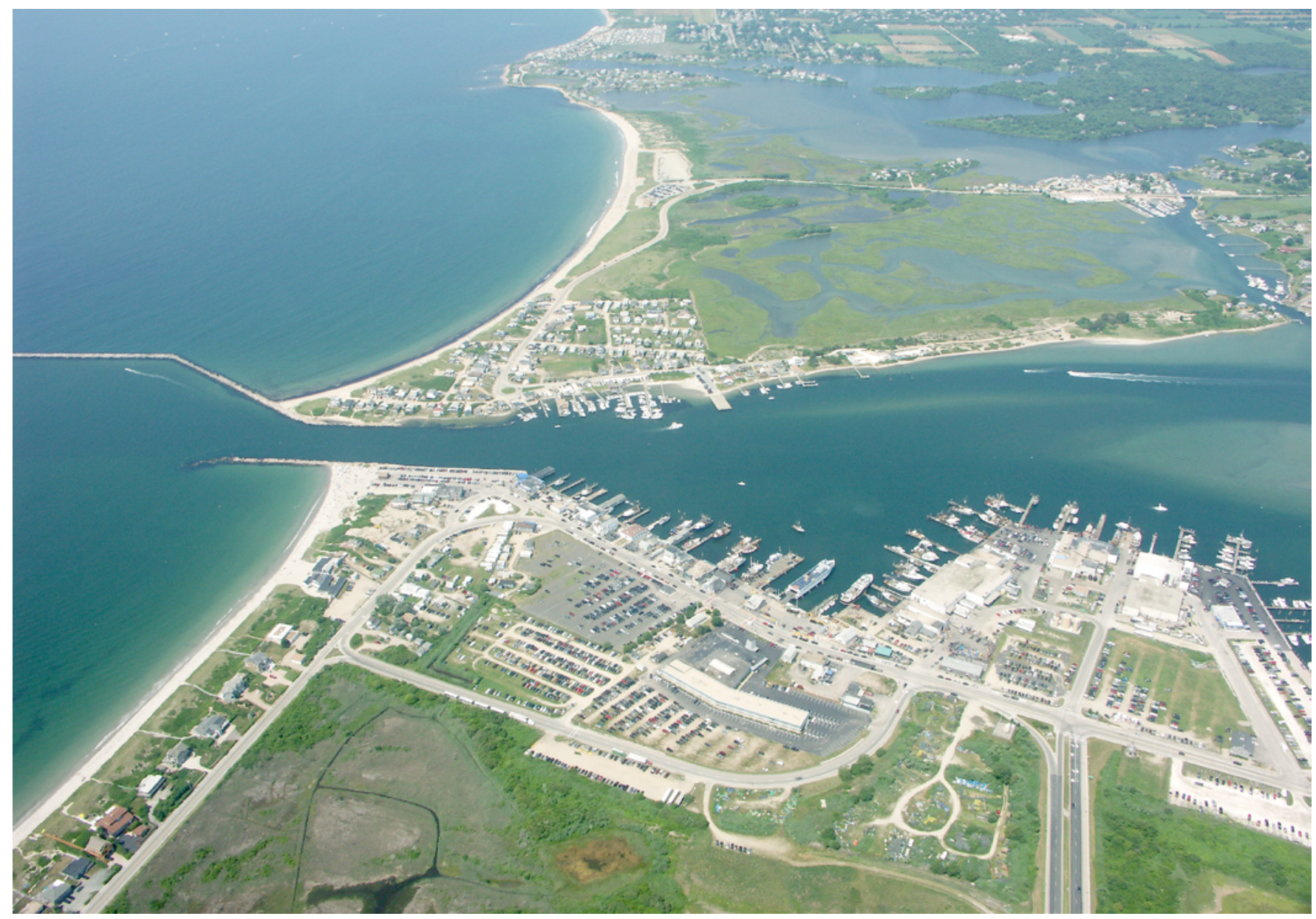

Open-File Report 2015-1046

U.S. Department of the Interior

U.S. Geological Survey 
Cover. Point Judith Pond (a small estuary) in Rhode Island, and the adjacent ocean. This area, viewed here from 1,000 feet, shows a variety of resources and uses colocated at a density that is increasingly common along coastal water bodies. Evidence of varied human uses can be seen as recreational and commercial fishing vessels, two public beaches, a commercial ferry, and a U.S. Coast Guard station. Associated infrastructure is prevalent along many sections of the coast. The surrounding ecosystem includes sandy beaches; marsh and seagrass habitats; and an abundance of living resources inhabiting the productive estuary and ocean. This area is a popular location for recreational uses, including swimming, paddling, sailing, fishing and gathering from shore, wildlife viewing, and kayak fishing and, as a result, is of special ecological, economic, and social importance to the region. Photograph by Giancarlo Cicchetti, U.S. Environmental Protection Agency. 


\section{ఇUSGS}

Prepared in cooperation with the U.S. Environmental Protection Agency and the National Oceanic and Atmospheric Administration

\section{Data Categories for Marine Planning}

By Frances L. Lightsom, Giancarlo Cicchetti, and Charles M. Wahle

Open-File Report 2015-1046

U.S. Department of the Interior

U.S. Geological Survey 


\title{
U.S. Department of the Interior SALLY JEWELL, Secretary
}

\section{U.S. Geological Survey \\ Suzette M. Kimball, Acting Director}

U.S. Geological Survey, Reston, Virginia: 2015

\begin{abstract}
For more information on the USGS - the Federal source for science about the Earth, its natural and living resources, natural hazards, and the environment-visit http://www.usgs.gov/ or call 1-888-ASK-USGS (1-888-275-8747).

For an overview of USGS information products, including maps, imagery, and publications, visit http://www.usgs.gov/pubprod/.
\end{abstract}

Any use of trade, firm, or product names is for descriptive purposes only and does not imply endorsement by the U.S. Government.

Although this information product, for the most part, is in the public domain, it also may contain copyrighted materials as noted in the text. Permission to reproduce copyrighted items must be secured from the copyright owner.

Suggested citation:

Lightsom, F.L., Cicchetti, Giancarlo, and Wahle, C.M., 2015, Data categories for marine planning: U.S. Geological Survey Open-File Report 2015-1046., 27 p., http://dx.doi.org/10.3133/ofr20151046.

ISSN 2331-1258 (online) 


\section{Contents}

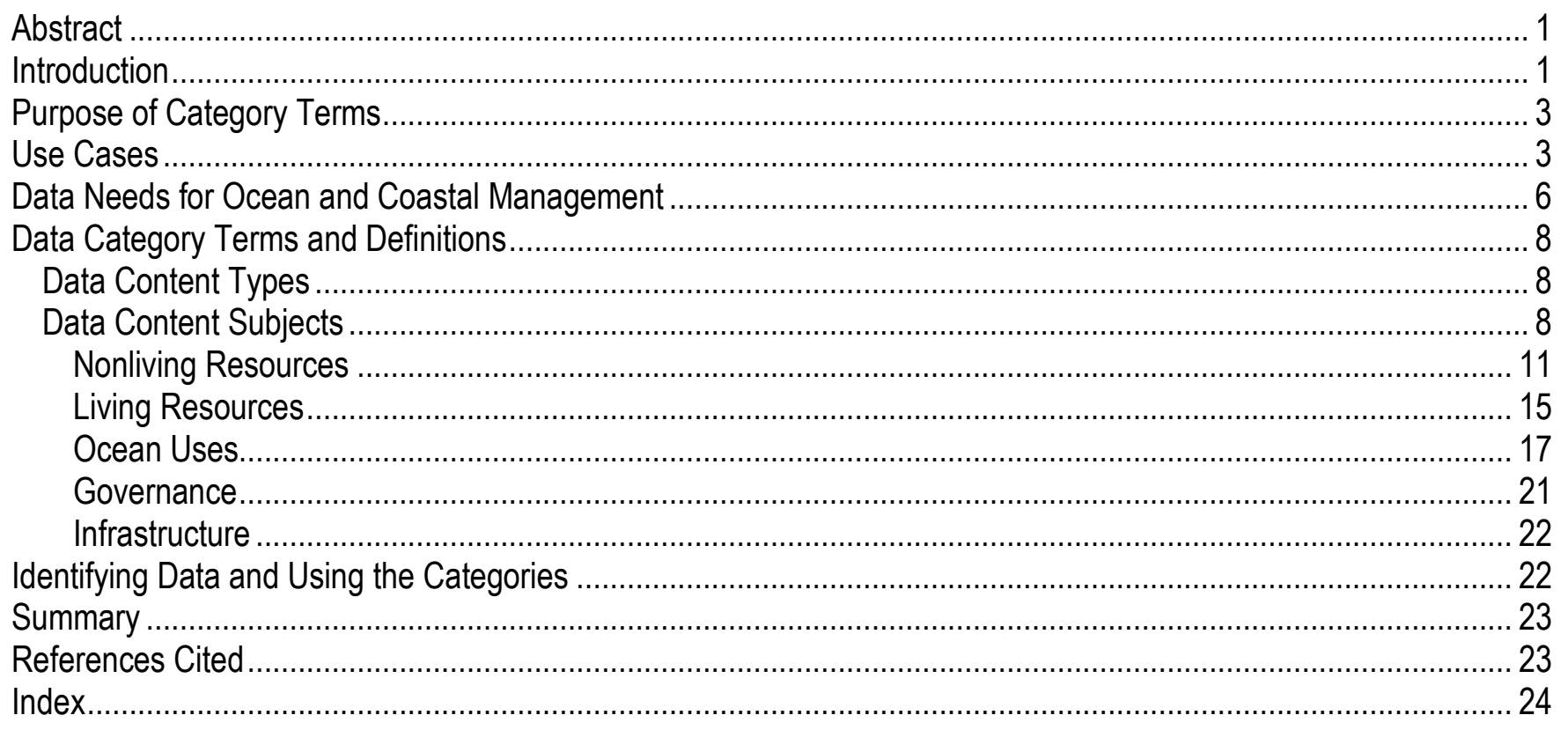

\section{Figure}

1. Diagram showing the three use cases describe the utility of the data categories for marine planning

\section{Abbreviations}

$\begin{array}{ll}\text { CMECS } & \text { Coastal and Marine Ecological Classification Standard } \\ \text { CMSP } & \text { coastal and marine spatial planning } \\ \text { GIS } & \text { geographic information system } \\ \text { MPA } & \text { marine protected area } \\ \text { NOAA } & \text { National Oceanic and Atmospheric Administration } \\ \text { NOC } & \text { National Ocean Council } \\ \text { NOP } & \text { National Ocean Policy } \\ \text { OTEC } & \text { ocean thermal energy conversion } \\ \text { USGS } & \text { U.S. Geological Survey }\end{array}$




\title{
Data Categories for Marine Planning
}

\author{
By Frances L. Lightsom, ${ }^{1}$ Giancarlo Cicchetti, ${ }^{2}$ and Charles M. Wahle ${ }^{3}$
}

\begin{abstract}
The U.S. National Ocean Policy calls for a science- and ecosystem-based approach to comprehensive planning and management of human activities and their impacts on America's oceans. The Ocean Community in Data.gov is an outcome of 2010-2011 work by an interagency working group charged with designing a national information management system to support ocean planning. Within the working group, a smaller team developed a list of the data categories specifically relevant to marine planning. This set of categories is an important consensus statement of the breadth of information types required for ocean planning from a national, multidisciplinary perspective. Although the categories were described in a working document in 2011, they have not yet been fully implemented explicitly in online services or geospatial metadata, in part because authoritative definitions were not created formally. This document describes the purpose of the data categories, provides definitions, and identifies relations among the categories and between the categories and external standards. It is intended to be used by ocean data providers, managers, and users in order to provide a transparent and consistent framework for organizing and describing complex information about marine ecosystems and their connections to humans.
\end{abstract}

\section{Introduction}

The U.S. Federal Government provides public access to government information and data through an official Web site called Data.gov. Data.gov is a catalog that integrates records describing data from hundreds of sources that cover the full range of governmental concerns. Although the promise of Data.gov is that everyone can find and use the data for illuminating and profitable purposes, as the volume of data grows, potential users face challenges finding the specific data they need within the expanding universe of available offerings. Large online data catalogs can address this challenge by using controlled vocabularies and sets of logical data categories. Controlled vocabularies allow the records to be labeled with terms that can be efficiently searched by users who are familiar with the concepts the vocabularies represent. A well-crafted set of categories can be used to sort, browse, and discover data, meeting the community's needs. Within Data.gov several community Web sites offer data discovery customized for particular user communities. An Ocean Community (http://www.data.gov/community/ocean) was sponsored by the interagency National Ocean Council (NOC) to implement the U.S. National Ocean Policy (NOP).

\footnotetext{
${ }^{1}$ U.S. Geological Survey.

${ }^{2}$ U.S. Environmental Protection Agency.

${ }^{3}$ National Oceanic and Atmospheric Administration.
} 
On July 19, 2010, the President issued Executive Order 13547, "Stewardship of the Ocean, Our Coasts, and the Great Lakes" (3 CFR EO 13547; http://www.gpo.gov/fdsys/pkg/FR2010-07-22/pdf/2010-18169.pdf), which enacted a new National Ocean Policy as set forth in the "Final Recommendations of the Interagency Ocean Policy Task Force" document (White House Council on Environmental Quality, 2010, hereafter referred to as the "Final Recommendations"). The recommendations include a framework for guiding regional implementation of coastal and marine spatial planning (CMSP). In an effort to provide an information foundation for CMSP, the NOC established the Interagency Information Management System and CMSP Data Portal Working Group in 2010. The working group then created the Information Needs Team charged with identifying the broad categories of ocean data considered most vital to effective CMSP.

The members of the 2010-2011 Information Needs Team were the following:

Charles Wahle
Craig Alvord
Wendy Blake-Coleman
Tai-Ming Chang
Giancarlo Cicchetti
Captain Robin Fitch
Patrick Gilman
John Haines
Kevin Kirby
Cliff McCreedy
Michael Rasser
Mary Boatman

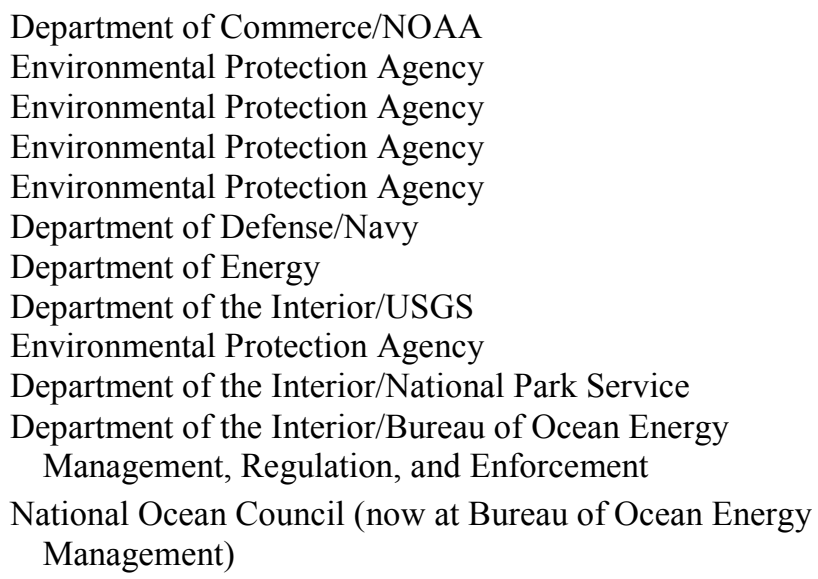

The team included a mix of agencies, departments, and services, with representation from agency planners and scientists with subject expertise. This group worked for 4 months to develop and organize a set of categories that would meet the needs of coastal and marine spatial planning. In an internal working document submitted to NOC in March 2011, this team listed a set of broad data categories and defined their purposes as follows:

- To guide the design and execution of the prototype national information management system and data portal required by the NOP;

- To help inform the CMSP Regional Planning Bodies' identification of regional objectives for the sustainable use and conservation of specific coastal, marine and Great Lakes areas;

- To help inform and prioritize data synthesis and assessment efforts by CMSP Regional Planning Bodies; and,

- To help identify critical gaps in scientific information needed for CMSP and other forms of spatial management in the United States.

Although the categories were described in 2011, authoritative definitions were not created formally, and the list was not disseminated beyond the NOC. Consequently, the full potential of this effort as an aid for organizing, finding, and communicating U.S. ocean data was not fully realized.

The primary purpose of the present report is to update this earlier work to establish a formal data vocabulary (with definitions) to further CMSP and other NOP goals. Specific and authoritative definitions, unique category names, connections with other standards, and additional pieces of information were developed, refined, and incorporated by the authors. The 
categories are intended to be provided online through vocabulary services that would interface with data catalogs and metadata creation tools. The online vocabulary services would include a governance process that allows for the addition of new categories and modification of existing terms to meet unanticipated needs. This publication, by the U.S. Geological Survey (USGS), in cooperation with the U.S. Environmental Protection Agency and the National Oceanic and Atmospheric Administration (NOAA), is intended for broad circulation to assist scientists, managers, and information specialists involved in CMSP and can be used by a more general audience as well.

\section{Purpose of Category Terms}

The category terms can be used to achieve the goals of three user classes, as summarized in the "Use Cases" section and shown in figure 1. The members of CMSP Regional Planning Bodies ultimately benefit from the terms but might not make direct use of them, instead relying on regional databases produced by geographic information system (GIS) specialists.

- As described in Use Case 1, data specialists in Federal agencies can use the categories to submit records to Data.gov that will be identified and properly classified as part of the ocean planning data system. A data specialist can use the category definitions to identify and prioritize agency data for marine planning. Data category terms used in metadata as keywords can identify the records for the ocean planning data system and assist in their appropriate classification within the ocean planning data system.

- As described in Use Case 2, the Federal committee maintaining the ocean planning data system can use the categories not only as a source of search keywords for identifying potential new records but also as a framework for organizing the ocean planning data system: the structure of categories can be provided as a browse tree, the records can be tagged with category names for more efficient searching, and links to the category definitions can be provided to assist data system users. The records in the ocean planning data system will be selected from among those submitted to Data.gov by Federal agencies.

- As described in Use Case 3, a GIS specialist supporting a regional planning body can use the categories as a reference in defining different types of data that are needed, as a checklist in tracking progress toward meeting data requirements, and as a source of terms to use in searching and browsing for data. A major resource used by the GIS specialist is the national ocean planning data system, which is a catalog of data selected and organized by a Federal committee.

The value of the data categories will increase if the ocean planning data system includes a comment form that collects information about additional data types that are needed. These types would be evaluated for inclusion in future versions of the data categories list.

\section{Use Cases}

Use cases describe plausible scenarios wherein specific data practitioners and data consumers use the ocean data categories to accomplish a goal related to marine planning. These descriptions show common examples of actions necessary for successful marine planning. 


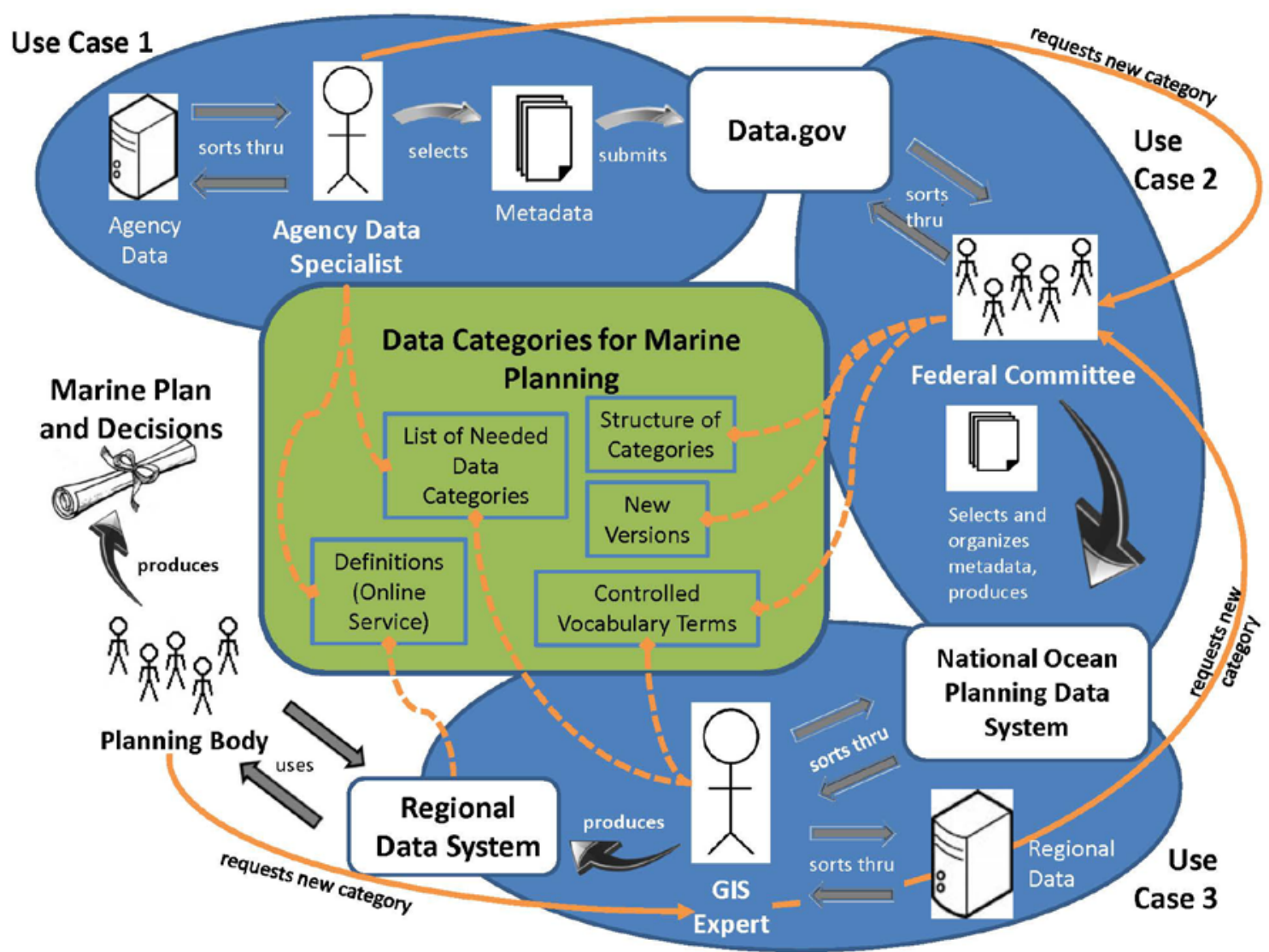

Figure 1. The three use cases describe the utility of the data categories for marine planning. In Use Case 1 (top left), an agency data specialist consults the categories to select metadata for submission to Data.gov. In Use Case 2 (top right), a Federal committee uses the categories to select metadata from Data.gov and organize it in a national ocean planning data system. In Use Case 3 (bottom), a geographic information system (GIS) expert in charge of a regional data system uses the categories to select data from both the national ocean planning data system and other regional data sources. Finally, as shown at the lower left, a regional planning body makes use of the regional data system to produce a marine plan and decisions. The dashed orange lines link these use cases to the elements of this report and future online Web services. As shown by the solid orange arrows, when the categories are provided online through Web services, a governance process will enable updates at the request of stakeholders. 
Use Case 1: Provide Metadata for National Ocean Planning Data System

Summary

A data specialist at a Federal agency identifies datasets and improves metadata records that are submitted to Data.gov to be included and properly classified within the national ocean planning data system.

Possible actions and use of "Data Categories for Marine Planning"

A data specialist at a Federal agency has responsibility for ensuring that the agency's data are made available to support regional marine planning activities. The data specialist begins by searching the agency's data holdings for relevant data. When relevant datasets are identified, they are prioritized to reflect their value for marine planning and the amount of work required to allow their release to the public. As data are prepared, the data specialist updates metadata records to meet Data.gov standards and adds keywords that flag the data for inclusion in the national ocean planning data system.

The data specialist uses "Data Categories for Marine Planning" as a source of data category definitions to identify and prioritize agency data for marine planning. Data category terms are used as keywords for identifying the records for the ocean planning data system and for ensuring that these records are appropriately classified within the ocean planning data system. If the data specialist discovers additional data that would be useful for marine planning but do not fit within the categories, this information is submitted to the ocean planning data system and evaluated for inclusion in future versions of the data categories list.

Use Case 2: Organize Catalog for National Ocean Planning Data System

Summary

A Federal committee selects and organizes data within Data.gov to create a national ocean planning data system that can be used to locate and acquire data in support of regional marine planning activities.

Possible actions and use of "Data Categories for Marine Planning”

The National Ocean Council establishes an interagency committee to develop and manage a national ocean planning data system that provides data, information, and decision tools for regional marine planning activities. The ocean planning data system is a topic section of the Data.gov system (www.data.gov). The committee sets up procedures for identifying relevant data within Data.gov and organizing the selected data. Web feeds are used to discover new Data.gov records that might be suitable for the ocean planning data system. These metadata records are evaluated to ensure that they meet topical and quality standards and are tagged for inclusion in the ocean planning data system. Additional tags are added to the records so that the data system can be efficiently searched and browsed.

In addition to a source of search keywords for identifying potential new records, the committee uses "Data Categories for Marine Planning" to organize the data provided through the ocean planning data system: the structure of categories is provided as a browse tree; the records are tagged with category names for more efficient searching; and links to the category definitions are provided to assist data system users. The ocean planning data system includes a comment form that collects information about additional data types that are needed, which are evaluated for inclusion in future versions of the data categories list. 
Use Case 3: Compile Data for CMSP Regional Planning Body

Summary

A geographic information system (GIS) specialist on the staff of a State agency compiles a data collection for the deliberations of a CMSP Regional Planning Body in creating a marine plan.

Possible actions and use of "Data Categories for Marine Planning"

A regional Governors' alliance agrees to form a regional planning body to produce a marine plan. The Governors have several concerns that they hope the plan will address:

1. They hope to expedite the approval and siting of offshore alternative energy projects while avoiding harm to their own State's ocean resources due to projects sited in Federal waters or the waters of other States.

2. They need to engage in long-term planning for changes in their fishing industry with the decline of fish stocks and climate change.

3. They want to make siting decisions for marine protected areas (MPAs), offshore oil drilling, and other large projects to minimize any adverse impacts and ensure that the involved States share benefits and risks.

4. They would like to influence management of pollution and nutrients flowing down a river in one State, then impacting the shell-fishing and beaches in another State.

The alliance accepts the offer of one Governor to instruct that State's GIS office to compile an initial collection of data to start the planning process. A GIS specialist is assigned the task. After researching the fisheries, endangered species, and marine industries that are important in the region, the specialist uses the national ocean planning data system to discover what data are easily available and downloads the data. The specialist imports the data into a GIS system, analyzes to identify data gaps, and calls colleagues in the region's research institutes to locate additional data. The specialist delivers a GIS product based on a comprehensive assemblage of datasets relevant to regional planning needs.

The GIS specialist uses "Data Categories for Marine Planning" as a reference to define different types of data that are needed, a checklist to track progress in meeting data requirements, and a source of terms to use in searching and browsing for data.

\section{Data Needs for Ocean and Coastal Management}

Coastal and marine spatial planning (CMSP) is both a goal and a foundational core component of the National Ocean Policy under Executive Order 13547 and the "Final Recommendations" document. The policy recognizes that current sector-specific management does not adequately evaluate the tradeoffs and environmental impacts associated with multiple human uses such as commerce, recreation, energy development, conservation, national security, and the traditional practices of indigenous peoples. The CMSP process provides a foundation for the transition to ecosystem-based management of coastal and marine resources that considers both ecological and human needs. The policy also recognizes that sound scientific understanding is essential to achieving an integrated decision-making process that includes knowledge of ecosystems, existing and evolving environmental conditions, and the potential consequences of natural and anthropogenic events.

Comprehensive CMSP involves complex analyses of the statuses and potential uses of three-dimensional areas of coastal, marine and Great Lakes ecosystems (including the water column) and their potential changes over time. Relevant spatial data and derived analytical products inform all phases of the CMSP process, including identification of regional objectives 
for the long-term use and conservation of specific areas; assessment of the status and trends of ecosystems, resources, and human uses; and creation, long-term implementation, and adaptive management of comprehensive plans to sustainably match those uses to appropriate areas.

To this end, the National Ocean Policy's "Framework for Effective Coastal and Marine Spatial Planning" (part 4 of the "Final Recommendations" document) identifies several key science and data issues inherent to informed regional decision-making about how and where human uses should occur in U.S. waters (listed here verbatim):

- Important physical and ecological patterns and processes (e.g., basic habitat distributions and critical habitat functions) that occur in the planning area, including their response to changing conditions;

- The ecological condition and relative ecological importance or values of areas within the planning area, including identification of areas of particular ecological importance, using regionally-developed evaluation and prioritization schemes that are consistent with national guidance provided by the NOC;

- The economic and environmental benefits and impacts of ocean, coastal, and Great Lakes uses in the region;

- The relationships and linkages within and among regional ecosystems, including neighboring regions both within and outside the planning area, and the impacts of anticipated human uses on those connections;

- Important ecosystem services in the planning area and their vulnerability or resilience to the effects of human uses, natural hazards, and global climate change;

- The spatial distribution of, and conflicts and compatibilities among, current and emerging ocean uses in the area;

- The contributions of existing place-based management measures and authorities; and,

- Future requirements of existing and emerging ocean, coastal, and Great Lakes uses.

As was noted in the 2010 "Final Recommendations" document, the science and management of coastal and ocean resources must be linked in ways that ensure that critical information about priority management needs is collected, synthesized, and conveyed to appropriate decision-makers. Often, however, communication between science and management is challenged by confusion over terminology, and by the dearth of consistent, transparent, and widely applicable schemes for classifying, organizing and serving data. As a result of these inconsistencies, evaluating data for even a single State or a small region is often difficult. Yet the Nation is now experiencing an explosion of information as better tools for data collection are developed. Acoustic, light detection and ranging, aerial, satellite, remotely operated and autonomous vehicles, glider, and underwater imaging tools allow the collection of geospatial data at an unprecedented rate. Meanwhile, several national coastal and ocean standards have recently emerged, notably the Coastal and Marine Ecological Classification Standard, or CMECS (Federal Geographic Data Committee, 2012; see http://coast.noaa.gov/digitalcoast/publications/cmecs), and the NOAA Common Language of Ocean Uses (Wahle and Townsend, 2013; see http://marineprotectedareas.noaa.gov/dataanalysis/ocean_uses/). These documents are thorough and consistent classifications of types of data about ecology and human uses of marine ecosystems. Now more than ever, collection, organization, communication, and application of coastal and marine data to the Nation's ocean policy depend on an agreed-upon high level of organization. The data categories and controlled vocabulary provided in this document fill a gap in structuring and defining those critically needed data. 
Beyond direct applications for categorizing and searching CMSP datasets, this vocabulary has other uses. The organizational structure behind the vocabulary facilitates identification of data gaps and development of research priorities, and it leads to further development of a variety of analytical and mapping tools. If the category names are used as keywords for technical publications and research proposals, they can assist in identifying knowledge gaps and coordinating efforts to fill the gaps. In short, using a common language to describe our information needs and assets for CMSP supports the goals of National Ocean Policy and other efforts through improved data access and sharing.

\section{Data Category Terms and Definitions}

The Information Needs Team recognized in 2010 that regional CMSP processes will draw upon a wide range of scientific information from a variety of sources for help in crafting and implementing comprehensive plans. The team identified a set of information that provides guidance in collecting appropriate information for both the National Information Management System and the CMSP Regional Planning Bodies in 2011. In this document we organize this information into defined and consistent categories of "data content type" and "data content subject."

\section{Data Content Types}

For most subjects, marine planning and decision-making require three different types of data content:

- Distributions describe locations or patterns of a feature of interest across space and (or) time. These data can include point data, lines, polygons, and temporal data at any scale relevant to CMSP and can be produced by observation, interpolation, or modeling. Distributions can also include maps or statistics of climatology, the environmental values that are expected to be observed at the present time.

- Assessments are derived data that provide information about the values, impacts, drivers, connections, or functions of a feature in its present distribution.

- $\quad$ Predictions are data expressing projections or models of future distributions, values, or impacts, including forecasts of anticipated changes brought about by natural and human processes, as well as scenario-testing models that compare outcomes of different management actions.

Individual data products often contain more than one set of data and might be described with more than one category of data content type.

\section{Data Content Subjects}

Comprehensive CMSP requires data about a variety of aspects of the ecosystems and human uses in the planning area. Specifically, the data content subjects required for marine planning include environmental characteristics and processes as well as human activities that use, rely on, or impact those features. For most data content subjects, CMSP requirements include specific data within each data content type (Distributions, Assessments, and Predictions), as listed below. In the following data subject categories and terms, "resources" are defined as any natural or anthropogenic features of the planning area that either reflect or influence the status, trends, or value of the area's natural and cultural resources and the ecosystem services these resources provide. Broad categories of data content subjects include the following: 
- Nonliving Resources

- Living Resources

- Ocean Uses

- Governance

- Infrastructure

All data content subject terms are organized in a hierarchy. These five broad, top-level categories include tiers of subcategories as relevant to marine planning. A data product can be labeled with as many subject categories or subcategories as are appropriate. The subcategory structure is designed to be transitive so that assigning the data subject at a subcategory level implies inclusion in an associated broader category. The full hierarchy is shown below. 


\section{Hierarchy of Data Content Subjects}

\begin{tabular}{|c|c|}
\hline Nonliving Resources & Ocean Uses-Continued \\
\hline Energy Resources & Harvesting Living Resources \\
\hline Oil Resources & Pelagic Fishing \\
\hline Natural Gas Resources & Fishing with Benthic Mobile Gear \\
\hline Wind & Fishing with Benthic Fixed Gear \\
\hline Tides & Kayak Fishing \\
\hline Ocean Currents & Dive Fishing \\
\hline Geothermal Resources & Fishing from Shore \\
\hline Ocean Thermal Resources & Gathering from Shore \\
\hline Solar Radiation & Offshore Seaweed Harvest \\
\hline Material Resources & Hunting \\
\hline Sand Resources & Energy Production \\
\hline Mineral Resources & Wind Energy Production \\
\hline Physical/Chemical Features & Wave Energy Production \\
\hline Physical Habitats and Geomorphology & Ocean Current Energy Production \\
\hline Bathymetry and Elevation & Tidal Current Energy Production \\
\hline Substrate & Ocean Thermal Energy Conversion \\
\hline Water Column Features & Offshore Oil and Gas Production \\
\hline Water-Quality Parameters & Transportation \\
\hline Living Resources & $\begin{array}{l}\text { Shipping } \\
\text { Cruise Ships }\end{array}$ \\
\hline Habitat & Military Vessels \\
\hline Ecological Functions and Services & Other Commercial/Industrial Uses \\
\hline Biological Production & Mining and Mineral Extraction \\
\hline Biodiversity & Offshore Aquaculture \\
\hline Biological Occurrence & Coastal Aquaculture \\
\hline Fishes & Seawater Intake \\
\hline Invertebrates & Sewage Discharge \\
\hline Flora & Ocean Dumping \\
\hline Mammals & Underwater Transmission Cables \\
\hline Birds & \\
\hline Reptiles & Governance \\
\hline Invasive Species & Marine Protected Areas (MPAs) \\
\hline Ocean Uses & Commercial Leases \\
\hline Recreational Nonextractive /Cultural Use & Jurisdictional Boundaries \\
\hline Scuba/Snorkeling & Tribally Governed Areas \\
\hline Swimming & Regulatory Use Restrictions \\
\hline Surface Board Sports & \\
\hline Paddling & Infrastructure \\
\hline Sailing & Ports \\
\hline Motorized Boating & Cables, Pipelines, and Power Grids \\
\hline Wildlife Viewing at Sea & Buoys and Navigational Aids \\
\hline Tide Pooling & Structures \\
\hline Shore Use & \\
\hline Cultural Use & \\
\hline
\end{tabular}




\section{Nonliving Resources}

"Nonliving Resources" data are about chemical, physical, or geological features that are of use or importance to humans or ecologies. This broad, top-level category of data content subjects includes three subcategories: "Energy Resources," "Material Resources," and "Physical/Chemical Features." Each of these includes several sublevels. These are defined in greater detail to further describe the data content types needed for each subject.

Energy Resources. - "Energy Resources" refers to natural features that provide a capacity to do work through combustion, movement, radiation, or heat; these resources include oil, natural gas, coal, wind, sun, currents, tides, and natural heat gradients. Distributions are recorded observations, maps, or models of specified resources at known locations, in some cases as a function of season or other temporal scales. Assessments are evaluations of the economic or ecological value associated with the resources or of the difficulty, environmental effects, or sustainability of energy extraction and production. Some assessments can appropriately be included in the "Energy Resources" category and also in related "Living Resources" or "Uses" categories. Predictions are the results of models or projections of future distributions, values, or impacts of energy resources; these data include forecasts of changes due to natural and human processes, such as resource losses or gains under different rates of resource extraction, effects of climate change, and so on. The "Energy Resources" subcategory includes eight sublevels.

- "Oil Resources" refers to deposits of valuable liquid hydrocarbons or fossil fuels. Distributions are geologic maps, models, and observations that indicate location, volume, and geochemical composition of underground deposits. Assessments evaluate locations, methods, and profitability of oil extraction and transportation; environmental impacts; and interactions with other uses. Predictions are the results of models or projections of future oil reserves based on extraction or natural processes, or they are predicted changes in profitability and risk due to economic, regulatory, technological, and environmental changes.

- "Natural Gas Resources" refers to stocks of naturally formed hydrocarbon gases, which are usually associated with petroleum fields or gas hydrate formations. Distributions are geologic maps, models, and other observations that indicate locations and volumes of underground stocks. Assessments evaluate locations, methods, and profitability of gas extraction and transportation; environmental impacts; and (or) other interactions with other uses. Predictions are the results of models or projections of future gas reserves based on projected extraction, or they are predicted changes in profitability and risk due to economic, regulatory, technological, and environmental changes.

- "Wind" refers to the natural movement of air in horizontal currents. Distributions are maps of wind climatology and observations of wind speed, direction, and variability in the lower atmosphere as a function of location, time, or elevation. Assessments evaluate the potential, profitability, and risks of generating wind energy, as well as the effects of wind on uses other than energy generation, such as transportation or offshore structures. Predictions are the results of models or projections of future wind climatology and wind assessments; these data include predicted changes due to economic, regulatory, technological, and environmental changes.

- "Tides" refers to the motions of water in ebb and flood currents, driven by the gravitational attraction of the Sun and moon on the Earth, at times influenced by wind events. Distributions are observations of tidal height, currents, and cycles, at specific locations and times, and they include maps of tidal climatology based on combinations of observations, astronomy, hydrodynamic theory, and numerical models. Assessments evaluate tidal energy potential, technologies, and risks; model the effects of tides on other uses; and evaluate risks associated with extreme tides. Predictions are the results of models or projections of future tidal 
climatology, tidal energy potential, effects, and risks; these data include predicted changes due to economic, regulatory, technological, and environmental changes.

- "Ocean Currents" refers to relatively constant directional flows of large water masses, which can be driven by a variety of dynamic forces. Distributions are observations of current speed and flow volume, as a function of location, time, and depth, and they include maps of ocean current climatology generated from oceanographic and weather observations, analysis of other driving forces, hydrodynamic theory, and numerical models. Assessments evaluate technology, locations, and profitability for using ocean currents to generate energy; they also evaluate effects of currents on biological resources and on other uses such as transportation or the extraction of resources. Predictions are the results of models or projections of future currents, energy potential, effects, and risks; these data include predicted changes due to economic, regulatory, technological, and environmental changes.

- "Geothermal Resources" includes temperature differences related to the Earth's internal heat, commonly observed as springs or vents discharging hot water or steam, or through geothermal wells positioned to extract heat. Distributions are direct observations of the temperature and flow volume of springs, vents, or deep-lying heat sources, as well as geologic and hydraulic models that estimate the location, temperature, and flow rate of hot water. Assessments evaluate geothermal energy potential, risks, and effects on other resources and uses. Predictions are the results of models or projections of future energy potential, risks, and effects; these data include predicted changes due to economic, regulatory, technological, and environmental changes.

- "Ocean Thermal Resources" includes the temperature differences between surface and deep waters in the ocean that can be used for electricity generation through ocean thermal energy conversion (OTEC). Distributions are observations of the ocean temperature profile as a function of time and location as well as maps of ocean temperature climatology based on observations and theory. Assessments evaluate technologies, locations, profitability, and risk of OTEC energy generation. Predictions are the results of models or projections of future OTEC energy potential, effects, and risks; these data include predicted changes due to economic, regulatory, technological, and environmental changes.

- "Solar Radiation" refers to energy emitted by the Sun in the form of electromagnetic waves and particles. Distributions are maps of sunlight climatology as well as basic weather observations such as incident solar radiation and cloud cover. Assessments evaluate the profitability, suitable locations, and effects of solar energy generation on biological resources and other uses.

Predictions are the results of models or projections of future solar energy potential, effects, and risks; these data include predicted changes due to economic, regulatory, technological, and environmental changes.

Material Resources.- "Material Resources" refers to significant quantities of any naturally occurring nonliving substances that humans can potentially use for economic, nutritional, recreational, ecological, aesthetic, and other benefits. This category does not include energy resources, which are discussed previously. Distributions are recorded observations, interpreted data, or models of specified resources at known times and locations and can include added tangible information for the resource in question (for example, thickness of deposit). Assessments are evaluations of total resource availability, economic value, ecological function and value, drivers, difficulty of extraction, and sustainability; larger assessments that combine "Resources" and "Uses" categories can appropriately be included both here and in the other related "Resources" or "Uses" categories. Predictions are the results of models or projections of future distributions, values, or impacts of material resources; these data include modeled changes to resources due to natural and human processes. Examples include models of resource losses or gains under different rates of resource extraction, deposition, natural removal, and accumulation; models of how changes to one resource can affect other resources or uses; and models that compare 
outcomes of different management actions. The "Material Resources" subcategory includes two sublevels.

- "Sand Resources" includes deposits of unconsolidated particles of biogenic or mineral sediments with a dominant particle size ranging from 0.0625-2.0 millimeters in diameter; the deposits may be located offshore as sand beds or onshore as dunes and beaches. Distributions are recorded observations or models of sediment size, composition, and deposit thickness in a location or area, including maps of sand resources compiled through observations, interpreted data, remote sensing data, geologic maps, and hydrodynamic models. Assessments are evaluations of total sand availability; models of present sand deposition and resuspension rates; models of difficulty of extraction, relocation, or protection; and models of ecological and economic value.

Predictions are the results of models or projections of future distributions, values, or ecological impacts of sand resources; these data include predicted changes to sand beds due to natural and human forces; scenario-based models of sand resource losses or gains under different management strategies of mining, extraction, relocation, dredging-related deposition, beach nourishment, or hard structure placement (for example, on beaches); and projections of the effects of human alterations to sand resources on other resources or on ecological function.

- "Mineral Resources" includes natural occurrences of any useful inorganic element or compound with particle sizes other than sand, including clay, silt, gravel, and bedrock (that is, substrate with a grain size other than 0.0625-2.0 millimeters; for finer subdivisions, see Federal Geographic Data Committee, 2012 [CMECS]). Distributions are recorded observations or models of mineral grain size, composition, and deposit thickness in a location or area, including maps of these resources derived through observations, interpreted data, remote sensing data, geologic maps, and hydrodynamic models. Assessments are evaluations of total mineral availability; models of present deposition, resuspension, erosion, or accretion; models of difficulty of extraction or relocation; and models of ecological and economic values. Predictions are the results of models or projections of future distributions, values, or ecological impacts of mineral resources; these data include predicted changes due to natural and human forces. Predictions are also the results of scenario-based models of resource losses, gains, or impacts on ecological or economic values under different management strategies (for example, mining, extraction, or relocation) or other human alterations.

Physical/Chemical Features._- "Physical/Chemical Features" are geological, chemical, or hydrodynamic features that are ecologically important or influence patterns of human uses of the ocean. Examples include seamounts, persistent upwelling zones, areas of low dissolved oxygen, and areas of reduced $\mathrm{pH}$. Distributions are recorded observations of parameters and features, often as a function of time as well as place, also including maps and three-dimensional predictions of distributions based on combinations of observations and theory. Distributions of physical and chemical features (for example, physical habitat, substrate, or bathymetry) are often used as data to support habitat-biota models.

Assessments provide information about the value, impact, drivers, connections, or functions of a feature in its present distributions, or they evaluate the effects of physical/chemical features on ecology or suitability for use. Assessments can include climate change models that project environmental effects of climate change and acidification. Larger assessments that combine physical/chemical features with other "Resources" and "Uses" categories can appropriately be included here and also in the other related "Resources" or "Uses" categories. Predictions are the results of models or projections of future distributions, values, or impacts, which include anticipated changes produced by natural and human processes, and they are also the results of scenario-testing models for comparing outcomes of different management actions. The "Physical/Chemical Features" subcategory includes seven sublevels.

- "Physical Habitats and Geomorphology" includes measures of the geologic and structural characteristics of the coast or sea floor, such as the features defined in the Geoform Component 
of CMECS. Distributions are detailed topographic and bathymetric maps, geolocated photographs, or sea-floor descriptions; Distributions includes maps that interpret observations to categorize areas on the basis of geoform types such as those in CMECS. Assessment types include evaluations of ecological or human use value and can include models that project environmental or economic effects of erosion, climate change, dredging, and other stressors. Predictions are the results of models or projections of future distributions, values, or ecological impacts of physical habitats, including predicted changes due to natural and human forces; they are also from scenario-based models of resource losses, gains, or impacts on ecological or economic values under different management strategies (for example, mining, removal, relocation, or the building of structures).

- "Bathymetry and Elevation" includes measures of the height of a location above or below a reference surface. Bathymetry is the elevation of the Earth's surface beneath a body of water, especially the ocean, typically determined by measurements of depth from the water surface at mean lower low water. Distributions are topographic maps and bathymetric charts based on collected data and also include smoothed or gridded maps of bathymetry and elevation from observational data or other associated factors. Assessment data types include models of ecological value, economic value, or current rates of alterations due to erosion, accretion, climate change, and other stressors (for example, wetland habitat loss). Predictions are the results of models or projections of future distributions, values, or ecological impacts of bathymetry, including predicted changes due to natural and human forces such as erosion, deposition, sea-level rise, and dredging activities; predictions also include the results of scenariobased models of bathymetry changes under different management strategies.

- "Substrate" represents the character and composition of the surface and near surface of the sea floor in subtidal or intertidal areas, as defined in the Substrate Component of CMECS or in similar classification systems. Distributions are records of substrate characteristics based on visual or photographic inspection or on analysis of samples and cores, and they also include interpretive maps classifying areas on the basis of combinations of observations, hydrodynamic models, or geological models. Assessments include evaluations of present ecological or economic values of substrate distributions, drivers of substrate change, and functions of substrates. Predictions are the results of models or projections of future substrate distributions, values, or ecological impacts, including predicted substrate changes due to natural and human forces including erosion, accretion, sea-level change, extraction, trawling, or other factors; and they are the results of scenario-based models of substrate changes on ecological or economic values under different management strategies or other human alterations.

- "Water Column Features" includes persistent or regularly occurring waves, layers, water masses, upwellings, stratifications, and fronts that are defined by patterns of water velocity, physical properties, and biogeochemical properties; these features are listed and defined in the "Layer," "Hydroform," and "Biogeochemical Feature" layers of the Water Column Component of CMECS. Distributions are records of currents, physical properties, or biogeochemical water properties, often based on shipboard surveys or coastal monitoring programs, and maps of currents or water property climatology, which indicate the expected locations of features under present conditions or apply a classification structure like that of CMECS. Assessments are data that provide information about the ecological or economic values, impacts, drivers, connections, or functions of water column features in their present distributions. Predictions are the results of models projecting future changes to currents or other persistent oceanographic features (for example, clines, stratification, connectivity, linkages, and zones of separation) due to climate change, ice-cap melt, and changing freshwater inputs; models predicting the ecological or 
economic impacts of these changes; and scenario-testing models comparing ecological or economic outcomes of different management actions.

- "Water-Quality Parameters" includes measures of the ranges and distributions of the chemical, physical, and biological constituents of waters, including temperature, salinity, $\mathrm{pH}$, dissolved oxygen, turbidity, total suspended solids, chlorophyll, nutrients, bacteria, and toxicants.

Distributions are recorded observations as a function of time and place, including measures of one or more parameters; maps that use observations and consider hydrodynamic factors to estimate present distributions or ranges; or categorizations of areas using classification systems such as CMECS to identify ranges. Assessments evaluate the current ecological, human health, or economic effects, values, or harms linked to water-quality parameters as well as evaluating effects on ecosystems, biotic distributions, and ecological processes. In the case of temperature, this includes ecological, industrial, and human service values but does not include values related to energy production, which are covered in the "Energy Resources" category. Predictions are the results of models or projections of future distributions, values, and human health or ecological impacts of water-quality parameters; Predictions include predicted effects due to changes in climate, industrial or residential needs, land use, or other natural and human forces and include scenario-based models of the impacts of changes to parameters on ecological, human health, or economic values under different management strategies or other human alterations.

\section{Living Resources}

"Living Resources" is a top-level category that includes aspects of coastal and marine biota that are of particular importance to ecology or to human uses. These can include particular species, groups of biota, associations of biota with physical features, biological function, and biological connectivity. "Living Resources" is divided into three subcategories: "Habitat," "Ecological Functions and Services," and "Biological Occurrence."

Habitat.- "Habitat" includes data that describe repeatable combinations of biota and associated chemical, physical, or geological features in a distinct place, which, as in the CMECS Biotic Component, generally are named for the dominant taxa living there. "Habitat" also includes biotopes in accordance with CMECS. Examples include seagrass beds, deep-water corals, benthos, nekton, plankton, mussel beds. Distributions for "Habitat" data subject types include records of biotic associations, habitats, or biotopes obtained through direct observation, imagery, collection, or other methods; Distributions also include biotope maps, "predicted" maps of present-day habitats (for example, the Northwest Atlantic Marine Ecoregional Assessment, Mapping European Seabed Habitats), and other compilations or interpretations from observed data. Assessments include ecological valuation indices, presence, quantity (hectares), or percentage of identified high-value habitats; other purposedriven, regionally-specific indicators of ecological value; classifications of areas as critical habitat; ecological services models; evaluations of habitat condition; and place-based indices of susceptibility and vulnerability to disturbance. Predictions are the results of models or projections of future distributions, values, or impacts; anticipated changes produced by natural and human processes; future projections of cumulative impacts of single or multiple stressors; and scenario-testing habitat loss/gain models and predictions of related ecological or economic effects under different management strategies. Ecological Functions and Services.- “Ecological Functions and Services" includes data describing or measuring an ecological or ecosystem process, property, or benefit to humans that is associated with habitat or biota. While many natural services are related to physical materials and energy production, this category is limited to those services and benefits that derive from ecological interactions of living organisms. Examples of processes or properties include primary productivity, secondary production, nutrient processing, biomass, biodiversity, ecological integrity, and trophic connectivity or export. 
Examples of services include provisioning of food; carbon storage; nutrient removal; filtration of water; and storm, wave, or flood protection. Functions and services related to biodiversity and production are included here and are further categorized and discussed below. Distributions include records of ecological processes, properties, or services at a location, obtained through direct measurement; measurement of proxies; or modeled estimates. Assessments include ecological valuation indices; calculations of yield; indices of habitat quality or biological integrity; purpose-driven, regionallyspecific indicators of ecological value or condition; classifications of areas as critical to certain functions; monetization or other valuations of services; and models of benefits or values. Predictions are the results of models or projections of future distributions, values, or impacts of ecological functions or services; anticipated changes produced by natural and human processes; future projections of cumulative impacts of single or multiple stressors; scenario-testing models of loss or gain of function; and predictions of ecological or economic effects of functional changes under different management strategies. The "Ecological Functions and Services" category includes two sublevels, which are called out for their broad impact on other functions and services and for their frequent use in assessments.

- "Biological Production" refers to a measure of growth, reproduction, or yield of a biological system at any scale, together with the services provided. This includes primary production (the rate or extent to which new organic matter is created, usually through photosynthesis); secondary production (the rate or extent to which consumers multiply and grow); related concepts such as standing stock, biomass density, available biomass, trophic transfer, and sustainable yield; and services including not only provisioning of food but also the many other services that are enhanced by high biomass of specific organisms. Distributions include spatial records of chlorophyll concentration; growth rates or biomass of flora or fauna; trophic transfer; human consumption; flood control; or other services, derived through direct measurement, measurement of proxies, or models. Assessments can estimate, model, value, or monetize the ecological or service benefits and impacts of various forms or quantities of primary production or evaluate the effects of nutrients, shading, climate change, or other stressors on production and related services. Predictions are the results of models or projections of future distributions, values, or impacts, including anticipated changes produced by natural and human processes. Predictive models can also evaluate the ecosystem-level effects and impacts to ecological functions or services resulting from changing levels and shifting forms of primary or secondary production; scenario-testing models can compare the production or service outcomes of different management actions, including altering nutrient inputs, harvesting, or other actions.

- "Biodiversity" refers to a measure of the variety of organisms within a level of biological organization at any scale in a defined place. Types of biodiversity include genetic diversity; species diversity; guild, feeding group, or functional group diversity; habitat or biotope diversity; and any other measure of biological variety at a location. Biodiversity can be evaluated at levels of biological organization including taxonomic groups (for example, fishes), communities (for example, megafauna), habitats (for example, soft substrate, coral reef), or ecological systems (for example, number of habitats or biotopes in a managed embayment) and at spatial scales ranging from submeter to global. Biodiversity is widely viewed as critical to ecological functions, services, and economic benefits; changes in biodiversity have been closely linked to changes in the ways ecosystems function. Biodiversity is usually considered as an inherent ecosystem service. For purposes of marine planning, biodiversity measures that can be compared across the planning area are most valuable in decision-making. Distributions include quantifications of numbers of species, genetic types, taxonomic groups (for example, fishes), communities, or habitats at a place; diversity indices that can include rarity or relative abundance of types; measurements of proxies (for example, habitat types with known high or low numbers of species); or models. Assessments can estimate, value, monetize, or model the ecological 
function or service values and impacts of various aspects of biodiversity; identify biodiversity "hotspots"; or evaluate the effects of pollution, development, climate change, or other stressors on biodiversity. Predictions are the results of models or projections of future distributions, values, or impacts to biodiversity, including future changes produced by natural and human processes. Predictive models can also evaluate the ecosystem effects and ecological function or service impacts of altered biodiversity; scenario-testing models can compare ecological function or service outcomes of different management actions that affect biodiversity.

Biological Occurrence.- "Biological Occurrence" data identify different taxa together with the times and locations in which these particular organisms live. Distributions for these data subject types record observations of identifiable taxa at known times and places on the basis of captured samples, imagery, genetic testing, or other methods. Distributions also include single-taxon modeling approaches such as habitat suitability index models or essential fish habitat models; interpretations based on empirical correlations; population change models; connectivity estimates; or evaluations of migratory pathways and spawning grounds. Assessment types include spatially applicable indices for identifying and valuing regional taxa; classifications of species (for example, as harvested, protected, or invasive) as a function of location and time; evaluations of organism condition; assessments of stressor or disturbance effects on taxa, assemblages and communities; evaluations of ecological value of species (for example, keystone species, nonredundant species); taxon-based ecological services models; and place-based indices of susceptibility and vulnerability to disturbance. Predictions include evaluations of future impacts, distributions, and ecological or economic effects due to single or multiple stressors and other projected changes, as well as scenario-testing models of taxon losses/gains under different management options, usually combined with projections of related ecological or economic effects. These data content types apply to all hierarchical subtypes within "Biological Occurrence." Subtypes can be used to more specifically identify groups of special importance to marine planning. Multiple subtypes may be used for data products that include more than one taxon:

- "Fishes": bony and cartilaginous fishes, including primitive fish-like chordates.

- "Invertebrates": invertebrate fauna, including primitive non-fishlike chordates and taxa regionally identified as shellfish.

- "Flora": vascular plants, macroalgae, phytoplankton, or microbial communities.

- "Mammals": warm-blooded lactating vertebrates.

- "Birds": avian fauna, including flying and nonflying forms.

- "Reptiles": cold-blooded vertebrate fauna, typically with four limbs and scales.

- "Invasive Species": nonnative or introduced biota that may spread throughout their new habitats and cause harm to native species and their interactions, human health, or economies. This subtype may be used in addition to another "Biological Occurrence" subtype, if appropriate.

\section{Ocean Uses}

"Ocean Uses" is a top-level category of data about human activities that occur in, on, under, or immediately above the water in the Nation's coastal and marine environments. Humans use and engage with the oceans in a variety of ways and purposes. To provide an objective, transparent, and consistent means of describing, understanding, and planning for those diverse activities, NOAA's National Marine Protected Areas Center recently published "A Common Language of Ocean Uses" (Wahle and Townsend, 2013). This simple framework defines 35 distinct ways that people use the oceans in the United States. The framework describes each use from a "functional perspective," articulating in objective terms how and where the use typically operates in ocean space and what components it involves (for example, vessels, gear, and so on). The resulting use categories provide a means for aggregating functionally similar uses (for example, offshore recreational and commercial pelagic 
fishing), while allowing important distinctions to be made and explored within the categories (for example, uses pursued for commercial as opposed to recreational purposes).

These "Ocean Use" categories are included in this document as a proposed unifying framework for collecting, organizing, managing, and applying data on human uses of the oceans for CMSP and other place-based management efforts. Distributions are maps or other spatial representations of human uses of the ocean across space or over time. Assessments are evaluations of the trends, ecological requirements and impacts, demographics, socioeconomic drivers and benefits, and conflicts and compatibilities of other human uses of the ocean in its present distribution. Predictions are the results of projections of future distributions or implications of human uses of the ocean, including changes in response to human and natural processes, optimal locations, and trade-offs resulting from different management actions.

As an organizing tool, these uses are here divided into five groups, or sectors, reflecting commonalities of purpose and approach among similar uses.

Recreational Nonextractive/Cultural Use.-These are activities pursued by individuals or groups for the purposes of recreation, exercise, sport, cultural traditions, or spiritual renewal. Many involve people in, on, or under the water, often with a small vessel or dive gear. With the exception of "Cultural Use," which may include traditional harvest of certain resources by tribes or native peoples, all involve nonextractive activities.

- "Scuba/Snorkeling" includes scuba diving, surface supply diving, snorkeling (that is, free diving); it excludes activities that can be classified in the "Swimming" or "Dive Fishing" categories.

- "Swimming" includes short- and long-distance surface swimming at any distance from shore and body surfing; it excludes activities that can be classified in the "Scuba/Snorkeling" and "Surface Board Sports" categories.

- "Surface Board Sports" includes tow-in and paddle-in surfing, windsurfing, kite surfing, and sailboarding; it excludes activities that can be classified in the "Paddling," "Scuba/Snorkeling," and "Swimming" categories.

- "Paddling" includes kayaking, canoeing, rowing, outrigger paddling, and stand-up paddling; it excludes activities that can be classified in the "Motorized Boating" and "Surface Board Sports" categories.

- "Sailing" includes transit, mooring, motoring, or anchoring by sailboats, including sailing kayaks and canoes; it excludes activities that can be classified in the "Motorized Boating" and "Paddling" categories.

- "Motorized Boating" includes transit, mooring, or anchoring by motorized vessels, including personal watercraft, for commercial or recreational purposes; it excludes activities that can be classified in the "Fishing," "Wildlife Viewing at Sea," "Cruise Ships," "Shipping," and "Sailing" categories.

- "Wildlife Viewing at Sea" includes boat-based wildlife viewing at sea, usually on a commercial vessel; it excludes incidental wildlife viewing from shore or sea while pursuing other activities such as those that are classified in the "Motorized Boating," "Paddling," or "Sailing" categories.

- "Tide Pooling" includes the nonconsumptive use of the intertidal zone between high and low tides for recreational, scientific, or educational purposes; it excludes activities that can be classified in the "Harvesting from Shore" or "Shore Use" categories.

- "Shore Use" includes walking, running, digging, resting, collecting of shells, wildlife viewing, driving on the beach, camping, kite flying, bonfires, picnicking, dog walking, horseback riding, skim boarding, and related recreational activities; it excludes activities that can be classified in 
the "Tide Pooling," "Mining and Mineral Extraction," "Surface Board Sports," "Swimming," "Harvesting from Shore," or "Coastal Aquaculture" categories.

- "Cultural Use" includes traditional and current use of specific ocean, coastal, and shoreline areas by tribal and indigenous communities, based on the area's inherent cultural, spiritual, or aesthetic values and significance; it excludes activities that can be classified in other "Ocean Use" categories.

Harvesting Living Resources.-Many ocean uses revolve around fishing, harvesting, or hunting of animals and plants for either commercial or recreational purposes. In those cases, data can be tagged with the appropriate descriptor ("Commercial" or "Recreational") to allow more refined searches, such as "Recreational Pelagic Fishing" or "Commercial Fishing with Benthic Mobile Gear." Many of these uses involve vessels and specialized capture or harvesting gear.

- "Pelagic Fishing" includes the use of midwater trawling, purse seine, pelagic long-lines, handlines, harpoons, midwater gillnets, rod and reel, trolling, and buoys to catch pelagic fishes and mobile invertebrates; it excludes activities that can be classified in other "Ocean Use" categories.

- "Fishing with Benthic Mobile Gear" includes the use of rod and reel, trolling, trawling, dredging, and other mobile gear to catch benthic fishes and mobile invertebrates; it excludes activities that can be classified in other "Ocean Use" categories.

- "Fishing with Benthic Fixed Gear" includes the use of traps, pots, bottom long-lines, bottom or anchored gillnets, pound nets, weirs, and other types of bottom tending gear used to catch benthic fishes and invertebrates; it excludes activities that can be classified in other "Ocean Use" categories.

- "Kayak Fishing" includes hook and line fishing from kayaks or any similar vessels to catch fishes and mobile invertebrates; it excludes activities that can be classified in other "Ocean Use" categories.

- "Dive Fishing" includes the use of scuba diving, surface supply diving, or snorkeling (free diving) to spear or catch fishes and invertebrates; it excludes activities that can be classified in other "Ocean Use" categories.

- "Fishing from Shore" includes the use of rod and reel, crab traps, cast nets, or kites to catch fishes and mobile invertebrates near the shore or from piers and jetties; it excludes activities that can be classified in other "Ocean Use" categories.

- "Gathering from Shore" includes consumptive and (or) subsistence harvest in the intertidal zone of living marine plant or animal species for consumption, aquaria, recreation, education, or research; it excludes other forms of intertidal or coastal harvesting, such as activities that can be classified in the "Fishing from Shore," "Tide Pooling," "Offshore Seaweed Harvest," or "Coastal Aquaculture" categories.

- "Offshore Seaweed Harvest" includes large-scale commercial harvesting by machine, or limitedscale individual harvesting by hand from a small boat, of any species of benthic macroalgae; it excludes activities that can be classified in other "Ocean Use" categories, such as "Offshore Aquaculture," "Coastal Aquaculture," and "Tide Pooling."

- "Hunting" includes shore- and boat-based hunting of vertebrates, birds, mammals, and reptiles, including legally recognized hunting by tribal and indigenous communities; it excludes fishing and activities that can be classified in the "Cultural Use" category.

Energy Production. - In addition to the extraction of fossil fuels for energy, new uses are emerging from sources of renewable energy such as wind, waves, tides, and currents. All are industrial, commercial operations and involve relatively large and extensive fixed, installed infrastructure and associated devices for collecting and transmitting the resulting products to shore (for example, pipelines and cables). 
- "Wind Energy Production" includes the generation of electricity from wind power by using turbines and associated offshore infrastructure, including substructures, transmission hubs, cables and service platforms; it excludes onshore power grids as well as activities and infrastructure associated with other forms of energy generation.

- "Wave Energy Production" includes the generation of electricity from wave power by using fixed or floating wave energy capture devices; it excludes activities and infrastructure associated with other forms of energy generation.

- "Ocean Current Energy Production" includes the generation of electricity from ocean currents by using turbines, associated transmission hubs, generators, and cables; it excludes activities and infrastructure associated with other forms of energy generation.

- "Tidal Current Energy Production" includes the generation of electricity from tidal currents by using dams and turbines, associated transmission hubs, generators, and cables; it excludes activities and infrastructure associated with other forms of energy generation.

- "Ocean Thermal Energy Conversion" includes the generation of electricity from ocean temperature gradients by using closed-cycle, open-cycle, and hybrid conversion systems, and associated seawater intake systems and pipelines; it excludes activities and infrastructure associated with other forms of energy generation.

- "Offshore Oil and Gas Production" includes production and transportation of oil and gas as well as associated offshore infrastructure and pipelines; it excludes "Shipping" as well as activities and infrastructure associated with other forms of energy generation.

Transportation.-Among the oldest of human uses of the ocean, the movement of people, goods, and armies by ship remains a major component of the Nation's ocean use footprint. All involve the transit far offshore by large ships over long distances, with periodic passages into shallower waters for loading, offloading, repairs, refueling, and so on.

- "Shipping" includes transit, mooring, or anchoring by ships, ferries, and other large commercial vessels; it excludes activities that can be classified in the "Offshore Oil and Gas Production" and "Cruise Ships" categories.

- "Cruise Ships" includes transit, mooring, or anchoring for extended overnight recreational travel on commercial ships; it excludes activities that can be classified in the "Motorized Boating" and "Shipping" categories.

- "Military Vessels" includes transit of military vessels related to training activities, homeland security, search and rescue, ship and submarine maneuvers, and war games; it excludes wartime military operations.

Other Commercial / Industrial Uses.-The oceans of the United States are increasingly considered valuable areas for industrial and commercial operations ranging from mining to aquaculture. These uses typically involve heavy equipment and permanently installed infrastructure, commonly over an extensive spatial footprint.

- "Mining and Mineral Extraction" includes sand and gravel extraction, seabed mining for commercial minerals, dredging, and beach nourishment; it excludes energy production activities.

- "Offshore Aquaculture" includes cultivating and harvesting marine organisms offshore by using man-made enclosures that can be fixed, floating, or submerged (for example, nets, pens, and cages); it excludes aquaculture wholly pursued on land and activities that can be classified in the "Coastal Aquaculture" category.

- "Coastal Aquaculture" includes cultivating and harvesting marine organisms in the nearshore environment by using man-made enclosures that can be fixed, floating, or submerged (for example, nets, pens, and cages); it excludes aquaculture wholly pursued on land and activities that can be classified in the "Offshore Aquaculture" category. 
- "Seawater Intake" includes intake of seawater for desalination, power plant cooling, or other industrial uses as well as associated beach wells, offshore or submerged intake systems, and pipelines; it excludes intake related to sewage discharge, renewable energy production, or fishing.

- "Sewage Discharge" includes discharging of sewage and wastewater effluent from outfall areas as well as associated pipelines; it excludes activities that can be classified in the "Ocean Dumping" category.

- "Ocean Dumping" includes the deliberate, legal dumping of dredged spoils and other materials into ocean waters; it excludes activities that can be classified in the "Sewage Discharge" or "Mining and Mineral Extraction" categories.

- "Underwater Transmission Cables" includes cables installed on the sea floor to transmit data, communications, and electricity generated on land; it excludes lost fishing gear and other types of cables such as those that can be classified in "Energy Production" use categories.

\section{Governance}

"Governance" is a top-level category of data that represent the boundaries of geographic areas that are defined for governmental, administrative, or management purposes. Governance data for marine planning are those that identify governance entities that have effects on environmental processes or human activities that impact the coast, Great Lakes, or ocean. Distributions are maps representing authoritative boundaries (for examples, see http://marinecadastre.gov). Assessments are maps showing theoretical boundaries resulting from models, evaluations, or scenario-testing; or they are modeled values of bounded regions. Predictions are maps showing predicted boundaries based on expected outcomes or driven by variable parameters; or they are models predicting impacts of moving boundaries. All "Governance" data share these definitions for Distributions, Assessments, and Predictions. "Governance" data are divided into six subcategories, with no sublevels.

Marine Protected Areas (MPAs).- "Marine Protected Areas (MPAs)" data delineate areas where some or all of the natural and cultural resources are given a heightened level of protection through regulation or other effective means in order to achieve conservation or societal goals (http://marineprotectedareas.noaa.gov).

De Facto MPAs. - "De Facto MPAs" data delineate areas where human access and activities are restricted for reasons other than conservation. Examples include military operating areas, safety zones around offshore energy production facilities, industrial exclusion zones, and shellfish closures for waterquality reasons (http://marineprotectedareas.noaa.gov).

Commercial Leases. - "Commercial Leases" data delineate areas where special-use allocations are established by contracts that define who has permission to carry out particular activities in an area or zone defined by the contract.

Jurisdictional Boundaries._- "Jurisdictional Boundaries" data delineate domestic, tribal, and international areas established by a law or treaty that determines who has the authority to interpret, apply, and enforce the laws within those areas.

Tribally Governed Areas. - "Tribally Governed Areas" data delineate specific regions under the sovereignty of American Indian tribes who determine policy, actions, and other affairs.

Regulatory Use Restrictions. - "Regulatory Use Restrictions" data delineate specific locations for which some uses are restricted in order to meet regulatory goals (for example, regions in which Total Maximum Daily Loads have been defined for particular pollutants). 
Infrastructure

"Infrastructure" is a top-level category of data that represent the locations of permanent or temporary installations intended to support basic human activities or needs, including communication, transportation, shoreline protection, housing, recreation, and utilities. Data required for marine planning are limited to infrastructure that has effects on environmental processes or human activities that impact the coast, Great Lakes, or ocean. Distributions are maps representing current locations of structures and facilities. Assessments are maps showing theoretical or suitable locations resulting from models, evaluations, or other processes; or they are models that evaluate the ecological or economic impacts of existing infrastructure. Predictions are maps showing predicted locations based on expected outcomes or variable factors and drivers; or they are models that evaluate the ecological or economic effects of proposed, changed, or future infrastructure. All "Infrastructure" data share these definitions for Distributions, Assessments, and Predictions. "Infrastructure" data are divided into four subcategories, with no sublevels.

Ports.-Ports are locations with facilities for loading, unloading, docking, fueling, and repairing vessels. Cables, Pipelines, and Power Grids. - These are linear features for communication and transmission of electrical power, data, fluids, or other materials.

Buoys and Navigational Aids.-These are constructed markers that provide location-specific information.

Structures.-Structures are temporary, permanent, or abandoned constructed features on the coast, Great Lakes, or ocean, including piers, platforms, energy installations, communication towers, hardened shoreline protection, jetties, housing, shipwrecks, and more, but not including ports, cables, pipelines, power grids, buoys, or navigational aids.

\section{Identifying Data and Using the Categories}

Data for ocean planning should be tagged as belonging to at least two categories: one or more data content types and one or more data content subjects. For example, a dataset that provides locations of seabird nesting islands would be identified as follows: "Birds"; Distributions. Category terms are written in capital letters to make clear that these are specific definitions. Data subjects are hierarchically transitive, so the above dataset ("Birds"; Distributions) is implicitly included in the higher level hierarchical subject categories of "Living Resources" and "Biological Occurrence." The dataset will be tagged to be found in searches for "Living Resources," "Biological Occurrence," "Birds," or Distributions. The more specific a search term is, the more directly it leads data consumers to the desired data.

Multiple data content types and subjects apply to some data products. Consider if the above dataset were part of a large, integrated data product that provided not only locations of seabird nesting islands but also data on local boating and shipping patterns, with assessments of related seabird disturbance and predictions of nesting success scenarios under various management options related to the moving of channel markers or other official signage. This large data product would be tagged as follows: "Birds," "Motorized Boating," "Shipping," "Buoys and Navigational Aids"; Distributions, Assessments, Predictions. Implicit hierarchical data subject terms would include "Living Resources," "Biological Occurrence," "Ocean Uses," "Transportation," and "Infrastructure." Again, the data product could be found under any of these category terms, and it could be found with greater efficiency by entering more terms into the search. Data consumers interested in any aspect of these data would be served this data product together with all other data that relate to any search terms that were entered into the data portal search engine. 


\section{Summary}

The U.S. National Ocean Policy calls for cooperation among Federal agencies, States, and tribes to develop regional plans for ecosystem-based management to sustain multiple uses and improve the conservation of the ocean, coasts, and Great Lakes. A broad, solid and transparent foundation of science-based knowledge is essential to the success of the Policy. Central to this ambitious endeavor will be a clear, consistent and transparent way to express scientific ideas and to find and apply relevant data to explore and illustrate them. To this end, the necessary data categories were identified in 20102011 by the Interagency Information Management System and Coastal and Marine Spatial Planning (CMSP) Data Portal Working Group and are valuable for identifying the data necessary for effective and transparent ocean planning and coastal management, for organizing information within the Ocean Community at Data.gov and other marine-planning related portals, and for providing services to assist regional planners and resource managers in finding that information.

A controlled vocabulary based on these categories, created by the U.S. Geological Survey in cooperation with the U.S. Environmental Protection Agency and the National Oceanic and Atmospheric Administration, can also be used as consistent key words for publications or products related to CMSP. These three agencies have updated the categories to reflect recent work, clarified their meanings by defining them and relating them to other standards, and organized them by data content type and data content subject. Widespread adoption of these terms, most of which are already agreed upon by interagency consensus, can lead to more practical data referencing by data portals, to more efficient searches by data consumers, and thus to improved management of our coasts and oceans.

\section{References Cited}

Federal Geographic Data Committee, 2012, Coastal and marine ecological classification standard (CMECS): Federal Geographic Data Committee FGDC-STD-018-2012, 343 p., accessed February 16, 2015, at http://www.fgdc.gov/standards/projects/FGDC-standards-projects/cmecsfolder/CMECS_Version_06-2012_FINAL.pdf.

The President, 2010, Executive Order 13547-Stewardship of the ocean, our coasts, and the Great Lakes: Federal Register, v. 75, no. 140 (July 22, 2010), p. 43023-43027, accessed February 16, 2015, at http://www.gpo.gov/fdsys/pkg/FR-2010-07-22/pdf/2010-18169.pdf.

Wahle, Charles, and Townsend, Julia, 2013, A common language of ocean uses: Silver Spring, Md., National Oceanic and Atmospheric Administration, National Marine Protected Areas Center, Office of National Marine Sanctuaries, 10 p., accessed February 16, 2015, at http://marineprotectedareas.noaa.gov/pdf/helpfulresources/common_language_ocean_uses_11_14_2013_final.pdf.

White House Council on Environmental Quality, 2010, Final recommendations of the Interagency Ocean Policy Task Force-July 19, 2010: White House Council on Environmental Quality, 77 p. plus appendixes, accessed February 16, 2015, at http:/www.whitehouse.gov/files/documents/OPTF_FinalRecs.pdf. 


\section{Index}

\section{A}

Aquaculture, 20

Assessments, 8

\section{B}

Bacteria, 15

Bathymetry and Elevation, 14

Benthic Fixed Gear, 19

Benthic Mobile Gear, 19

Biodiversity, 16

Biological Occurrence, 17

Birds, 17

Boating. See Motorized Boating, Sailing

Buoys and Navigational Aids, 22

\section{C}

Cables. See Underwater Transmission Cables

Cables, Pipelines, and Power Grids, 22

Chlorophyll, 15

Climatology, 8

CMECS, 7, 13, 14

CMSP. See Coastal and Marine Spatial Planning

CMSP Data Portal Working Group, 2

Coastal and Marine Ecological Classification Standard. See CMECS

Coastal and Marine Spatial Planning, 2, 6

Coastal Aquaculture, 20

Commercial, 19, 20, 21

Commercial Leases, 21

Cruise Ships, 20

Cultural Use, 19, See Recreational / Nonextractive / Cultural Use

Current Energy Production. See Ocean Current Energy Production or Tidal Current Energy Production

\section{D}

Data Content Subjects, 8

Data Content Types, 8

Data.gov, 1, 23

De Facto MPA, 21

Dissolved Oxygen, 15

Distributions, 8

Dive Fishing, 19

Dumping. See Ocean Dumping

\section{E}

Energy Production, 19

Energy Resources, 11

Executive Order 13547, 2, 6, 23

\section{$\mathbf{F}$}

Final Recommendations, 2, 6, 7, 23

Final Recommendations of the Interagency Ocean Policy Task Force. See Final Recommendations 
Fishes, 17

Fishing from Shore, 19

Fishing with Benthic Fixed Gear, 19

Fishing with Benthic Mobile Gear, 19

Flora, 17

\section{G}

Gas. See Offshore Oil and Gas Production, Natural Gas, See Natural Gas

Gathering from Shore, 19

Geothermal Resources, 12

Governance, 21, 22

H

Habitat, 15

Harvesting Living Resources, 19

Hierarchy, 10

Hunting, 19

\section{1}

Industrial Uses. See Other Commercial / Industrial Uses

Information Needs Team, 2

Infrastructure, 22

Invasive Species, 17

Invertebrates, 17

J

Jurisdictional Boundaries, 21

K

Kayak Fishing, 19

Keywords, 8

$\mathbf{L}$

Living Resources, 15

\section{M}

Mammals, 17

Marine Protected Areas, 21

Material Resources, 12

Metadata, 3, 5

Military Vessels, 20

Mineral Resources, 13

Mining and Mineral Extraction, 20

Motorized Boating, 18

\section{N}

National Information Management System, 2

National Ocean Council, 1, 2

National Ocean Policy, 1, 2, 6, 7, 23

Natural Gas, 11

Navigational Aids. See Buoys and Navigational Aids

NOC. See National Ocean Council

Nonextractive. See Recreational / Nonextractive / Cultural Use 
Nonliving Resources, 11

NOP. See National Ocean Policy

Nutrients, 15

\section{0}

Ocean Current Energy Production, 20

Ocean Currents, 12

Ocean Dumping, 21

Ocean Thermal Energy Conversion, 20

Ocean Thermal Resources, 12

Ocean Uses, 17

Offshore Aquaculture, 20

Offshore Oil and Gas Production, 20

Offshore Seaweed Harvest, 19

Oil. See Offshore Oil and Gas Production, Oil Resources

Oil Resources, 11

OTEC. See Ocean Thermal Resources

Other Commercial / Industrial Uses, 20

\section{$\mathbf{P}$}

Paddling, 18

Pelagic Fishing, 19

Physical and Chemical Features, 13

Physical Habitats and Geomorphology, 13

Pipelines. See Cables, Pipelines, and Power Grids

Ports, 22

Power Grids. See Cables, Pipelines, and Power Grids

Predictions, 8

Production, 16

\section{$\mathbf{R}$}

Recreational, 18, 19

Recreational / Nonextractive / Cultural Use, 18

Regional Planning Bodies, 2

Regulatory Use Restrictions, 21

Reptiles, 17

Resources, 8

\section{S}

Sailing, 18

Salinity, 15

Sand Resources, 13

Scuba/Snorkeling, 18

Seawater Intake, 21

Seaweed. See Offshore Seaweed Harvest

Sewage Discharge, 21

Shipping, 20

Shore Use, 18

Snorkeling, 18

Solar Radiation, 12

Structures, 22

Substrate, 14

Surface Board Sports, 18

Swimming, 18 
Temperature, 15

Thermal, 12, 20

Tidal Current Energy Production, 20

Tide Pooling, 18

Tides, 11

Total Suspended Solids, 15

Toxicants, 15

Transmission Cables. See Underwater Transmission Cables

Transportation, 20

Tribally Governed Areas, 21

Turbidity, 15

\section{U}

Underwater Transmission Cables, 21

Use Case, 3

V

Vocabularies, 1

W

Water Column Features, 14

Wave Energy Production, 20

Wildlife Viewing at Sea, 18

Wind, 11

Wind Energy Production, 20

Working Group, 2 
Prepared by the Pembroke Publishing Service Center.

For more information concerning this report, contact:

Director

Woods Hole Coastal and Marine Science Center

U.S. Geological Survey

384 Woods Hole Road

Quissett Campus

Woods Hole, MA 02543-1598

WHSC_science_director@usgs.gov

508-548-8700 or 508-457-2200

or visit our Web site at:

http://woodshole.er.usgs.gov/ 
